\title{
Transformações do eu na velhice: consequências psíquicas e para a prática clínica*1
}

\section{Transformations of the ego in old age: psychic and clinical consequences}

\author{
Vanessa Biscardi Matos*2 \\ Fábio Roberto Rodrigues Belo*3
}

Este trabalho objetivou desenvolver subsídios para a psicanálise de velhos a partir da teoria laplancheana. A recorrência com que contingências do envelhecer impõem-se como força motriz para o trabalho psíquico, exige do analista pensar as implicações da velhice para o sujeito e para a prática clínica. Partimos da hipótese de que as vicissitudes da velhice tangenciam de modo particular o tema da sedução originária. A partir da leitura aos moldes de uma escuta clínica do livro a máquina de fazer espanhóis (mãe, 2016)," articulamos as peculiaridades da velhice relatadas aos aspectos teóricos referentes a uma atualização das mensagens enigmáticas e suas consequências para o psiquismo. Consideramos que em função da velhice ocorrem particulares transformações do eu que interferem nos processos de subjetivação e na condução do caso clínico.

Palavras-chave: Psicanálise, velhice, eu, teoria da sedução generalizada

*1 Trabalho baseado em dissertação acadêmica intitulada "Transformações do eu na velhice: estudo psicanalítico sobre algumas consequências psíquicas e para a prática clínica", apresentada em 18.2.2019 na Universidade Federal de Minas Gerais, realizada com apoio financeiro da Capes.

*2,3 Universidade Federal de Minas Gerais - UFMG (Belo Horizonte, MG, Brasil).

${ }^{1}$ Mantivemos a grafia em minúsculas do nome do autor e também de seus personagens, conforme a proposta do escritor. E também as citações em português de Portugal, conforme sua escrita. 


\section{Introdução}

Objetivamos desenvolver, a partir da teoria laplancheana, um aporte teórico que contribua para a psicanálise de velhos. Partirmos de questões suscitadas pela prática clínica, em atendimentos que possibilitaram perceber quão marcantes são as contingências experienciadas por sujeitos idosos. Na velhice, os sujeitos tendem a vivenciar perdas com maior frequência, bem como são impelidos a lidar de forma diferente de outros momentos da vida com o tempo, a morte e uma reorganização identificatória vinculada a um inexorável trabalho de luto.

Tais vivências são relatadas de forma recorrente na clínica como causadoras de sofrimento e de trabalho psíquico. Com Laplanche (1987/1992a), entendemos que trabalho psíquico significa uma exigência imposta pelo pulsional, exercida por protótipos inconscientes, e os processos de simbolização diminuem o seu aspecto coercitivo. Essa exigência é suscetível de certos aumentos e certas diminuições em decorrência dos próprios processos psíquicos.

Embasados na escuta clínica tanto da recorrência quanto do modo como esses conteúdos aparecem como força motriz para o trabalho psíquico de sujeitos idosos, interrogamos como a psicanálise auxilia a compreender essas questões. Partimos da hipótese de que a velhice tangencia, com alguma particularidade, o tema da sedução originária e da passividade concernente à teoria da sedução generalizada de Jean Laplanche. Esta hipótese diz respeito à formulação de que o corpo e as vicissitudes da velhice ocasionam uma atualização de mensagens enigmáticas e provocam transformações do eu. Desse modo, a escuta de sujeitos idosos nos levou a considerar que o inconsciente mantém-se preservado quanto às suas características e ao seu funcionamento, ao passo que a instância egoica sofre transformações que interferem nos processos de subjetivação e, consequentemente, exige pensar sobre a psicanálise de velhos. 


\section{ARTIGOS}

Norteados pela metodologia desenvolvida por Laplanche para pesquisa da obra freudiana, propomos neste estudo um retorno à teoria psicanalítica a fim de colocá-la a trabalho (Laplanche, 1987/1992a). Isto significa problematizar, questionar a partir de um tema de aparência clássica na psicanálise, colocando à prova, até os fundamentos, toda a experiência analítica para que, a partir disso, uma nova temática, novas ordenações, novos conceitos ou uma nova disposição dos conceitos se desenhe (Laplanche, 1987/1992a). Desse modo, retornamos à teoria da sedução generalizada articulando os seus elementos com o momento da velhice, bem como interrogando o que tal momento traz de implicações para o psiquismo, especificamente em relação à sua engrenagem denominada eu.

A fim de trazer elementos clínicos para compreender a relação entre a alteridade e a atemporalidade do inconsciente e as transformações do eu em sujeitos idosos, de acordo com a teoria laplancheana, recorremos à literatura. Freud (1907/1996b) indicou que os escritores criativos são aliados muito valiosos, cujo testemunho deve ser levado em alta conta. A análise de obras literárias foi um recurso bastante utilizado por ele visto que personagens podem comportar toda complexidade da subjetividade humana e, por isso, favorecer a compreensão do funcionamento psíquico. Assim, fazemos uma leitura do livro a máquina de fazer espanhóis, de valter hugo mãe (2016), nos moldes de uma escuta clínica.

Com seu estilo próprio de escrita, mantendo todas as palavras em letra minúscula e a pontuação reduzida a vírgulas e pontos finais, mãe (2016) compõe um enredo minucioso e sensível, recheado de detalhes sobre as vivências da velhice. $\mathrm{O}$ relato do personagem silva, de 84 anos, sobre os diversos acometimentos do corpo, as perdas e os sofridos lutos experienciados, bem como os recursos utilizados por ele para lidar com o que the era apresentado pelos acontecimentos intimamente relacionados ao envelhecer, nos serviu de material para análise. Partimos de uma construção teórica sobre as transformações do eu na velhice e, em seguida, utilizamos elementos do livro para exercitar o pensamento clínico quanto à teorização apresentada.

\section{Implicações da velhice para a psicanálise}

Em 1898, ao discorrer sobre "A sexualidade na etiologia das neuroses", Freud (1898/1996a) apresenta-se pessimista quanto à duração do tratamento de idosos visto um "acúmulo de material" que pode fazer coincidir o fim da 
análise com "um período de vida em que já não se dá valor à saúde nervosa" (p. 268). Em "O método psicanalítico", ele reafirma as "condições desfavoráveis à psicanálise" em uma idade próxima aos cinquenta $\operatorname{anos}^{2}$ em função da "acumulação de material psíquico" relacionada ao longo tempo necessário para recuperação, e acrescenta que "as possibilidades dos processos psíquicos acharem novos caminhos começam a se paralisar" (Freud, 1904/2017a, p. 396). E novamente, no mesmo ano, em "Sobre psicoterapia", Freud (1904/2017b) aponta a idade igual ou superior a cinquenta anos como uma contraindicação para o tratamento analítico devido à falta de "plasticidade dos processos anímicos nos quais a terapia se fia — pessoas idosas não são mais educáveis" e ao prolongamento indefinido do tratamento em função da quantidade do material a ser elaborado (p. 72). Porém, o próprio Freud antecipa que as suas contraindicações não podem ser pensadas como definitivas tendo em vista muitas limitações práticas que afetaram a sua atividade.

Há outros dois textos freudianos mais tardios nos quais encontram-se questões que apontam particularidades psíquicas associadas à idade, principalmente no desencadeamento das neuroses. Em "Sobre tipos neuróticos de adoecimento", Freud (1912/2016) destaca ser importante levar em conta como causa de enfermidade uma mudança interna. Ele destaca que "por haverem atingido um determinado período de vida, e em conformidade com processos biológicos regulares, a quantidade de libido em sua vida anímica sofreu uma intensificação", a qual "em si mesma é suficiente para perturbar o equilíbrio da saúde e estabelecer as condições para a neurose" (p. 77). Segundo Freud (1912/2016), "essas repentinas intensificações estão geralmente associadas à puberdade e à menopausa, quando as mulheres atingem determinada idade; além disso, em alguns seres humanos, elas se manifestam em periodicidades ainda desconhecidas" (p. 77).

Já em "A análise finita e a infinita", apesar de comparar o que ocorre na psicanálise de alguns jovens em termos de "relações e distribuições de força imutáveis, fixas e petrificadas" ao que ocorre com pessoas muito velhas "pelo chamado poder do hábito, do esgotamento da capacidade de absorção, o que se explica com uma espécie de entropia psíquica" (p. 348), Freud $(1937 / 2017$ c) explicita que "duas vezes ao longo do desenvolvimento individual surgem intensificações consideráveis de certas pulsões: na puberdade

\footnotetext{
${ }^{2}$ Pessoas com 50 anos eram consideradas idosas no início do século XX, antes da Primeira Grande Guerra, mais por fatores culturais do que por uma realidade biológica (Goldfarb, 2014).
} 


\section{ARTIGOS}

e por volta da menopausa nas mulheres" (pp. 327-328). Ele explica que "os recalques se comportam como os diques contra a pressão das águas" e "aquilo que essas intensificações fisiológicas da pulsão produzem pode ser igualmente provocado de forma irregular em qualquer outro momento de vida a partir de influências acidentais" (p. 328). E indica que "as intensificações das pulsões se originam a partir de novos traumas, impedimentos [Versagungen] impostos ou influenciamentos colaterais mútuos entre as pulsões", de modo que "o resultado será sempre o mesmo e ele endurece o poder irresistível do fator quantitativo na causação da doença" (p. 328). Nesse texto, Freud $(1937 / 2017 \mathrm{c})$ aponta que os seus desenvolvimentos teóricos até aquele momento ainda pareciam insuficientes para entender corretamente os grupos de casos que ele descrevia, além da necessidade aparente de se levar em conta que "características temporais, alterações de um ritmo de desenvolvimento na vida psíquica ainda não foram consideradas de modo adequado" (p. 348).

Cabe observar que nas publicações de 1898 e 1904, Freud afirma uma cristalização dos processos anímicos que podemos associar a certa rigidez dos mecanismos de defesa e do funcionamento do eu. Ao passo que nos escritos de 1912 e 1937, encontra-se em questão um aumento de excitação pulsional relacionada ao trauma. Tais alusões tangenciam dois componentes diferentes de uma mesma engrenagem psíquica, o eu e o isso, sustentadas por uma economia e uma dinâmica do aparelho psíquico. Dessa forma, podemos articular essas observações extraídas dos textos freudianos à hipótese de que as modificações corporais, junto aos acontecimentos contingenciais do envelhecimento, impõem sobre o psiquismo uma potência traumática que é força motriz para transformações do eu.

\section{Teoria da sedução generalizada e os contornos conferidos ao eu}

A teoria da sedução generalizada de Laplanche explica a constituição do psiquismo a partir de uma relação que toma o corpo como suporte privilegiado tanto da invasão sedutora do adulto sobre a criança, quanto das vias de metabolização dessa invasão originária (Ribeiro \& Carvalho, 2001). De acordo com Laplanche (1997), para haver constituição do psiquismo humano, é necessária uma interação entre dois lados radicalmente distintos, a qual é denominada situação originária: de um lado encontra-se o infante que, neste momento, é uma montagem biológica voltada inicialmente para uma finalidade complexa de autoconservação; de outro, o adulto que cuida desse 
pequeno organismo e, ao realizar tais cuidados, faz uso de significantes gestuais, mímicos ou sonoros que ocasionam a implantação de mensagens comprometidas com o seu inconsciente e, portanto, enigmáticas, sexuais, tanto para si mesmo quanto para o bebê. Esta é uma linha de articulação indissociável entre o psíquico e o somático pelo apoio.

Como destaca Laplanche (1997), "a sexualidade, mesmo sob as formas que ela toma no ser humano, só pode situar-se no corpo" (p. 14), de modo que, para esse autor, "a teoria da sedução traz a verdade do apoio" (p. 31). Tal explicação da gênese do aparelho psíquico a partir de um resgate em Freud do termo apoio e da sua melhor fundamentação, favorece a compreensão da afirmativa de Freud (1912/2019) de que "as primeiras satisfações sexuais se apoiam nas funções corporais necessárias para a conservação da vida" (p. 139). Assim, Freud introduziu a ideia e Laplanche melhor descreveu o apoio da pulsão sexual em uma função não sexual ligada à conservação da vida.

A sexualidade, que de início encontra-se inteiramente apoiada em uma função destinada a conservar a vida, em um movimento dissociativo, separa-se dela. $\mathrm{O}$ instinto enquanto função vital é pervertido pela sexualidade à medida que é introduzido na criança pela via das zonas erógenas, presentes no invólucro corporal e manipuladas pelo adulto a fim de garantir cuidados ao bebê, um corpo estranho interno: a excitação sexual. Em decorrência disso, a sexualidade vem cedo demais, trazida pelo mundo adulto, antes que a criança possua "correspondentes 'afetivos' e 'representativos' para integrar a cena sexual e "compreendê-la" (Laplanche, 1985, p. 50). Desse modo, a partir da relação cuidador-bebê, os cuidados veiculam e intrometem no universo da criança significações do mundo adulto, vão dando contorno às zonas erógenas e provocando uma excitação que, em um segundo momento, será reproduzida de modo autônomo por um estímulo interno. Essa excitação sexual forma "uma espécie de externo-interno, um 'espinho na carne', ou um verdadeiro espinho na crosta do ego" (Laplanche, 1985, p. 49).

Com Laplanche (1987/1992a), compreendemos a constituição do eu partindo da teoria freudiana do trauma em dois tempos. Em um primeiro momento, ocorre um ataque externo proveniente do adulto, da primeira cena sexual, para o qual o infante encontra-se despreparado para se defender com os meios adequados e pode, no máximo, enquistar a lembrança, mas não recalcá-la. Em um segundo tempo, a criança consegue compreender a cena, mas encontra-se atacada por uma lembrança e não por um acontecimento. Entre esses ataques externos e internos irá intervir o aparecimento do eu, a partir do processo de recalcamento. 


\section{ARTIGOS}

Segundo Laplanche (1987/1992a), "no primeiro tempo não há 'ego', ou, então, se já se quer empregar esse termo, é preciso dizer que ele coincide com o todo do indivíduo e, mais especificamente, com sua periferia que o delimita" (p. 142), sendo denominado por Freud ego-corpo. No segundo momento do recalcamento originário, o que está em questão é o começo do ego como instância, que é "uma parte do aparelho, à imagem do todo, é, portanto, metáfora do todo biológico, mas também órgão do todo, em continuidade metonímica com ele" (p. 142; grifo do autor). Desse modo, o eu-corporal e sua metaforização sob forma de instância no aparelho psíquico são constituídos a partir da sedução originária, como uma oposição ao caráter dispersivo e excessivo do sexual proveniente do outro, e como uma defesa psíquica contra o ataque interno pulsional (Ribeiro, 1997).

Cabe ressaltar que a instância egoica não é estática. As representações do eu apoiam-se nas mudanças do corpo que funcionam como fonte pulsional visto a sua imposição traumática e a atualização do enigma, levando o aparelho psíquico a trabalhar para simbolizar essas mudanças (Laplanche, 1987/1992a). Tal aspecto dinâmico do eu dialoga com a abordagem de Ribeiro (1997) quanto às suas indissolúveis relações com o inconsciente e a necessidade de o eu ser levado à morte durante o processo analítico.

Partindo da perspectiva de que a instância egoica não é apenas adaptativa à realidade ou uma imagem alienante a ser combatida pelo processo psicanalítico, o trabalho de perlaboração, assim como o trabalho do luto, consiste em um percurso de decomposição e recomposição do eu. Nesse percurso, durante a perlaboração, a morte do eu não significa sua definitiva consumação. Tal morte está vinculada a uma ideia de transformação que permite levarmos em conta a possibilidade de várias mortes do eu, bem como de uma análise que, mesmo tendo chegado ao fim, seja passível de ser recomeçada. Portanto, a perlaboração durante o processo analítico está estreitamente relacionada com o trabalho de luto, sendo ambos um trabalho do eu (Ribeiro, 1997).

\section{Transformações do eu na velhice}

Fazendo uma análise do texto freudiano "Sobre a transitoriedade", Ribeiro (1997) aponta que Freud debruça sobre o trabalho do luto para salientar a existência de um trabalho psíquico necessário ao desligamento da libido investida no objeto perdido. Para Ribeiro, "o sentimento de culpa da pessoa em luto, a ambivalência de seus sentimentos relativos ao morto e a 
retração quase total de seu interesse pelo mundo não deixam de sugerir uma perda quanto ao eu tão importante quanto na melancolia" (p. 42). A partir de tal raciocínio, ele argumenta que na economia libidinal tanto do luto, quanto da melancolia, a perda do objeto implica uma perda do eu, colocando em relevo o caráter narcísico e identificatório de toda escolha objetal.

Em decorrência disso, Ribeiro (1997) indica que o luto revela-se como um trabalho da instância egoica de decomposição e recomposição de si própria, o qual na perspectiva freudiana é um trabalho de análise, isto é, um partir em pedaços, um desligamento, cujo princípio pode ser transposto para a perlaboração enquanto trabalho indispensável ao tratamento psicanalítico. No entanto, enquanto no luto e na melancolia uma perda quanto ao eu é determinada por uma perda efetiva do objeto, a qual condena o eu ao trabalho, na perlaboração a perda é verificada ao fim do trabalho e será sempre o equivalente a uma morte do eu. Em síntese, "no luto a perda leva ao trabalho, enquanto na perlaboração o trabalho leva à perda" (p. 42).

Consideramos que fora do processo analítico também ocorrem mortes do eu e, na velhice, muito frequentemente, há tanto perdas que levam ao trabalho psíquico, quanto uma imposição de trabalho psíquico que leva a perdas, transformações do eu, tendo em vista o caráter indissociável entre o corpo e essa instância do psiquismo. Se as representações do eu apoiam-se nas mudanças do corpo, o corpo velho com perda de potência, jovialidade, beleza e todas as modificações a ele impostas, funciona como uma fonte pulsional que atualiza mensagens não traduzidas ou mensagens traduzidas que requerem destradução e retradução neste momento. O corpo, na velhice, ativa inscrições sexualizantes e junto às decorrentes formas de relacionar com o outro, o tempo, a finitude, intimamente ligadas ao corpo, desperta enigmas e impõe uma exigência de simbolização. Assim, tais vicissitudes da velhice levam a transformações do eu a partir do trabalho de luto e de perlaboração. A seguir, a fim de dar consistência aos pressupostos teóricos explorados, utilizamos como material clínico o livro a máquina de fazer espanhóis, de valter hugo mãe (2016).

\section{Análise de um caso exemplar: a máquina de fazer espanhóis}

antónio jorge da silva tem 84 anos, trabalhou como barbeiro e encontra-se aposentado. É pai de dois filhos, elisa e ricardo. elisa é casada, mãe de dois jovens, e mantém contato com o pai. ricardo é professor, mudou-se para a grécia há três anos para dar aula em uma universidade e, desde então, não 


\section{ARTIGOS}

regressou a portugal para estar com seus familiares, nem mesmo na ocasião do falecimento da sua mãe. Depois de ter escolhido não ir ao funeral da mãe, "era um filho sepultado" para o silva, segundo ele dizia. (mãe, 2016, p. 62)

A morte de laura, esposa do nosso protagonista, centraliza o desenrolar de toda a trama. Com a perda da companheira após 48 anos de convívio íntimo e afetuoso, em sua nova condição de viúvo e vivendo este luto, antónio é levado pela filha para uma instituição de longa permanência para idosos. No lar para idosos feliz idade, o silva relata muitas experiências, as quais identificamos como ilustrações potentes de uma reorganização identificatória vinculada a mudanças nos papéis sociais, solidão, alterações corpóreas e funcionais, angústias e novos vínculos, conforme apresentamos a seguir.

\section{A atualização de mensagens enigmáticas na velhice}

\section{Mensagens do outro e o marco subjetivo da velhice}

antónio inicia sua narrativa com a internação de laura devido a uma indisposição após o lanche. Ele apresenta-se angustiado durante as horas de espera por notícias da esposa devido ao medo de perdê-la e à necessidade de dormir longe dela após quase cinquenta anos de casados. Durante essa espera, silva diz:

a laura rir-se-ia de mim, sem dúvida. do modo como eu me deixava perder sem ela ao pé. precisas de uma mãe, dizia-me. eu queria pouco saber se aos oitenta e quatro anos via a minha própria mulher como a mãe necessária para uma sobrevivência equilibrada. era certo que me atrapalhavam todas as coisas que enfrentava sozinho. já há tanto estávamos no tempo da reforma, tão habituados a depender um do outro para o gasto dos dias, a alegria dos dias, e a gestão ainda de uma certa nostalgia dos filhos. ela não gostava muito que eu o pensasse, e menos ainda que o dissesse, mas era-me claro que já não mandávamos nos filhos, crescidos e independentes, fazendo isso com que parte dos nossos papéis ficassem vazios. era como morrer para determinadas coisas. (mãe, 2016, p. 31)

Nessa passagem, vemos silva às voltas com as mudanças de papéis sociais por ele desempenhados, processo intimamente relacionado a um rearranjo identificatório. Além disso, com essa fala, começamos a localizar como a sua companheira representa para ele uma atualização dos objetos de amor primordiais, dos cuidadores iniciais no momento em que o sujeito encontrava-se em situação de desamparo, de passividade radical. 
Após horas madrugada adentro no hospital, antónio recebe a notícia do falecimento da esposa, sendo a sua reação por ele descrita:

tombei no chão e, por um tempo, a consciência foi-se e eu pude ser ninguém, como as coisas deviam ser sempre nestas alturas. só depois gritei, imediatamente sem fôlego, porque aquela teoria de que existe oxigênio e usamos os pulmões e fica feito também não é cem por cento verdade. entrei em convulsões no chão e as mãos do homem e da mulher que ali me assistiam eram exactamente iguais às bocas dentadas de um bicho que me vinha devorar e que entrava por todos os lados do meu ser. fui atacado pelo horror como se o horror fosse material e ali tivesse vindo exclusivamente para mim. (mãe, 2016, p. 34)

Apreendemos desse trecho como a morte de laura impõe-se com violência como conteúdo traumático que coloca antónio a trabalho psíquico, ao que ele expõe o sentimento de ataque, de invasão. A sua fala quanto a um devoramento apresenta-se como uma metáfora, uma forma, mesmo que precária, de elaboração da morte e da perda deste objeto de amor.

Diante do ocorrido com a sua amada parceira, silva afirma ter ficado zangado e desejado aos outros pouco bem, além de ter sentido indiferença ou conforto diante do mal que lhes pudesse ocorrer. Isso é apresentado por ele associado ao que ele sentira como "uma alegriazinha ingénua, de tempo contado" das pessoas que foram lhe prestar solidariedade fazendo-o perceber o quanto ele também era ingênuo e despreparado para lidar com a aquela situação (mãe, 2016, p. 36):

que se fodam os discursos de falsa preocupação dessa gente que sorri diante de nós mas que pensa que é assim mesmo, afinal, estamos velhos e temos de morrer, um primeiro e o outro depois e está tudo muito bem. sorriem, umas palmadinhas nas costas, devagar que é velhinho, e depois vão-se embora para casa a esquecerem as coisas mais aborrecidas dos dias. onde ficamos nós, os velhinhos, uma gelatina de carne a amargar como para lá dos prazos. que ódio tão profundo nasce. como incrivelmente nos nasce alguma coisa num tempo que já supúnhamos tão estéril. (mãe, 2016, p. 37)

Observamos a sua vivência do luto relacionada a uma alteridade apresentada pelas pessoas à sua volta, bem como a uma alteridade interna que possibilita localizar a velhice como um estranho familiar. ${ }^{3}$ antónio vai dando

${ }^{3}$ Unheimlich, o estranho, é um termo utilizado por Freud (1919/1996d) para referir-se a uma ambiguidade, uma contradição, em algo que é, ao mesmo tempo, familiar por um lado e oculto por outro. Remete a conteúdos recalcados, portanto passíveis de estranheza, os quais não deixam de soar, ao mesmo tempo, algo familiares, visto o seu registro no psiquismo. 


\section{ARTIGOS}

contorno a um marco subjetivo que o impele a identificar-se como velho. Em sua história, tal marco encontra-se intimamente ligado às contingências negativas e às narrativas pejorativas sobre a velhice, as quais mobilizam afetos. Neste momento é necessário lidar com o imaginário dos outros quanto ao que é ser idoso, bem como com o seu, de forma que localizamos mais uma vez um trabalho de rearranjo identificatório.

As mensagens sobre a velhice possuem conteúdo enigmático, sexual, exigente de tradução. Desse modo, por mais que em alguns contextos pareça compreensível a morte na velhice, inclusive pelo próprio velho, algo pulsa à revelia do sujeito gerando manifestações incoerentes com esta racionalização. No caso de antónio, quatro meses após a morte de laura, ele fora levado pela filha para uma instituição de longa permanência para idosos chamada feliz idade e relata:

estou entregue, pensei. aos meus pés dois sacos de roupa e uma enfermeira dizendo coisas simples, convencida de que a idade mental de um idoso é, de facto, igual à de uma criança. o choque de ser assim tratado é tremendo e, numa primeira fase, fica-se sem reacção. se aquela enfermeira pudesse acabar com aquele sorriso, ao menos acabar com aquele sorriso, seria mais fácil para mim entender que os meus sentimentos valiam algo e que sofrer pela laura não vinha de uma lonjura alienígena, não era uma estupidez e, menos ainda, vinha de um crime para clausura e tudo. (mãe, 2016, p. 38)

Aqui nos deparamos com novas perdas sentidas pelo silva em relação à sua vida antes da morte de laura, junto à sensação de apassivamento e à percepção de infantilização pelo outro, bem como a uma demanda por legitimação pelo outro daquilo que sentia em decorrência do luto. A rapidez como com frequência, na nossa cultura o idoso é comparado à criança, representa uma aparente via facilitada de tradução sobre a velhice pelas suas características ligadas ao desamparo, à passividade, aos cuidados corporais despendidos no início da vida. Todavia, comparações da velhice com a infância tendem a não ressoar psiquicamente para os sujeitos idosos, quem de fato vive a velhice, dadas as diversidades das contingências que vão na contramão de um processo gradual de aumento de potências.

Ao chegar ao lar feliz idade, antónio constatou que a entrada de um novo morador no lugar era precedida pela morte de um antigo, e foi se percebendo como parte de um grupo de velhos: "tão na extremidade da vida eram todos a mesma coisa, um conjunto de abandonados a descontar pó ao invés de areia na ampulheta do pouco tempo" (mãe, 2016, pp. 43-44). Nos primeiros seis dias evitou ao máximo interagir com os demais moradores e considerações sobre a velhice surgiram: 
a esperança que se deposita na criança tem de ser inversa à que se dirige a nós. e quando eu fico bloqueado, tão irritado com isso sem dúvida, não é por estar imaturo e esperar vir a ser melhor, é por estar maduro de mais e ir como que apodrecendo, igual aos frutos. nós sabemos que erramos e sabemos que, na distracção cada vez maior, na perda de reflexos e de agilidade mental, fazemos coisas sem saber e não as fazemos por estupidez. fazemos por descoordenação entre o que está certo e o que nos parece certo e até sabemos que isso de certo ou errado é muito relativo. é tudo mais forte que nós. (mãe, 2016, p. 47)

É notório como a chegada ao lar feliz idade junto a todo o processo de rearranjo narcísico convoca antónio a lidar de forma diferente das outras fases da vida com o tempo. E se, por um lado, existem vias facilitadas de tradução do sexual atreladas ao passar do tempo como maturidade, experiência e sabedoria, por outro, há também vias tradutivas degradantes relacionadas aos acometimentos do corpo, à certa iminência da morte, à constatação da transitoriedade e da finitude, à impotência, conforme ocorre com silva.

Nesse contexto, reflexões sobre o tempo também tornaram-se recorrentes para ele. No seu relato, observamos a necessidade do outro para o sujeito diante do desamparo, nas origens e sempre, corroborando a nossa hipótese de atualização de mensagens enigmáticas na velhice com determinadas especificidades:

preparem-se sofredores do mundo, o tempo não é linear. o tempo vicia-se em ciclos que obedecem a lógicas distintas e que se vão sucedendo uns aos outros repondo o sofredor, e qualquer outro indivíduo, novamente num certo ponto de partida. (mãe, 2016, p. 119)

Há uma não linearidade do tempo atrelada ao desamparo das primeiras vezes, da necessidade do outro na situação originária enquanto infante, e nas posteriores atualizações dessa situação ao longo da vida. Na velhice, frente aos efeitos das constantes perdas de objetos de amor, há uma forte tendência à evidenciação de um desamparo ligado à sensação de involução dada a falibilidade do corpo e a constatação de sua própria finitude sentida lenta e progressivamente na carne.

A perda de uma potência sentida e localizada na juventude, coloca em questão outro luto referente à perda de uma parte de si mesmo, intimamente relacionada ao corpo e associada a uma localização temporal do momento da velhice. Os fragmentos acima possibilitam um paralelo entre o que ocorre na adolescência e o que acontece na velhice. Na adolescência, há um confronto entre um corpo recém-saído da infância que sofre modificações, ganha relevância inédita, e algo da sexualidade denominada adulta, reavivando inscrições originárias e a excitação que elas continuam a provocar (Ribeiro \& 


\section{ARTIGOS}

Carvalho, 2001). Na velhice, o corpo novamente tem uma relevância inédita, embora agora as grandes mudanças corporais sejam no sentido de uma redução de potência. Inscrições originárias são reavivadas com intensidade e impelem a simbolizações, mantendo-se algo do (des)encontro com a sexualidade denominada adulta.

Neste momento, aquilo que serve como sustentação ao narcisismo está fragilizado. Na afirmação de antónio — "é tudo mais forte que nós" — localizamos uma fragilidade do eu colocado a trabalho de reconstituição diante de tanto esgarçamento de seu tecido identificatório devido à força traumática que as mudanças corporais e os acontecimentos contingenciais ligados a elas impõem sobre o psiquismo. Assim, se a morte do eu durante o processo psicanalítico diz respeito à análise/desmontagem das identificações que, em conjunto, dão consistência ao eu, no caso da velhice é a (des)identificação entre eu e corpo que ocasiona a morte do eu e coloca o sujeito em trabalho de luto, na medida em que as imagens de si passam a não coincidir com os ideais identificatórios que davam consistência à articulação eu-corpo.

\section{Acolhimento e atualização das mensagens enigmáticas: novos vínculos, novos circuitos pulsionais}

Em sua primeira manhã no lar, silva foi acordado por américo, um jovem funcionário do lugar que lhe causou desde o primeiro contato boa impressão. antónio afirma que, ao acordá-lo, américo "fez um monólogo imaginativo" em que ele parecia responder-lhe, mas sem diminuí-lo "à condição de débil mental" ou à ingenuidade dos seus netos (mãe, 2016, p. 45). No decorrer dos dias e do contato próximo e afetuoso, américo tornou-se um amigo para silva. Foi a primeira pessoa com quem ele quis comunicar-se e também quem por diversas vezes o acolheu em situações difíceis.

o américo veio acudir-me e, mais uma vez, viu-me furioso atirando o candeeiro novamente ao chão e disposto a finalmente enlouquecer. e o américo quase me abraçava, eu repetindo, estão a entrar pelo som, andam nas vozes das pessoas e depois não temos mais como impedir que nos invadam. e ele dizia, é só o medo, senhor silva, não é gente, é o medo que se põe com maneiras de o apanhar. não vamos deixar que isso aconteça. (mãe, 2016, p. 63)

américo realiza uma contenção simbólica e um investimento libidinal em silva, auxiliando-o a elaborar o traumático. É ele quem parece, de algum modo, ir assumindo uma função de amparo na vida do silva, antes 
desempenhada por laura. Essa relação torna-se recurso psíquico para antónio lidar com a dor psíquica vivenciada e, a partir dela, vemos um estado melancólico ir dando espaço a um investimento em novos objetos de amor, fenômenos que oscilam e passam a conviver.

Após seis dias de silêncio permanente, antónio disse a primeira palavra no lar. senhor pereira, um morador do lugar, encontrava-se distraído em um pequeno terraço, com o corpo muito inclinado para frente, procurando pelo américo. Percebendo o risco de queda por distração, antónio aproximou-se e gritou "cuidado", ao que pereira endireitou-se e pôs-se a conversar sem assustar-se com a falta de outras palavras ou qualquer expressão facial do silva. A partir daí, gradualmente antónio conheceu e tornou-se amigo do pereira, do esteves e do anísio franco.

esteves era figura popular no lar, conhecida por ter inspirado os versos de Fernando Pessoa em seu poema Tabacaria. anísio franco, de 82 anos, era uma pessoa entusiasmada e cheia de projetos de saber mais e contar às pessoas através da escrita de livros. silva estabelece também com ele um vínculo afetivo e, a partir desse encontro, se depara com uma saída diferente frente ao envelhecer, ou seja, com certa heterogeneidade das velhices:

pasmava diante dele porque não concebia o que era chegar àquela idade e ter projectos. o meu projecto era esquecer tudo, era protestar contra a morte da laura convencendo-me de que, depois da morte de alguém que nos é essencial, ao menos a memória do amor deveria ser erradicada também. (mãe, 2016, p. 104)

Esses novos vínculos vão favorecendo uma ressignificação quanto ao estar vivo sem laura, bem como quanto à condição de ser velho com todas as reverberações que isto traz. Depreendemos tais considerações tanto dos excertos acima, como do seguinte relato:

este resto de vida, américo, que eu julguei já ser um excesso, uma aberração, deu-me estes amigos. e eu que nunca percebi a amizade, nunca esperei nada da solidariedade, apenas da contingência da coabitação, um certo ir obedecendo, ser carneiro. eu precisava deste resto de solidão para aprender sobre este resto de amizade. hoje percebo que tenho pena da minha laura por não ter sido ela a sobreviver-me e a encontrar nas suas dores caminhos quase insondáveis para novas realidades, para os outros. os outros, américo, justificam suficientemente a vida, e eu nunca o diria. (mãe, 2016, p. 244)

A relação com os amigos, essa possibilidade de novos e, no caso de antónio, inéditos vínculos na velhice, auxilia como recurso psíquico, afetivo, numa reconstituição da rede narcísica. Podemos pensar em uma reconfiguração 


\section{ARTIGOS}

do tecido narcísico a partir dos vínculos estabelecidos, do relatar a si mesmo, às figuras de afeto que fazem contenção simbólica, possibilitando uma transformação do eu na velhice abrangente não só de perda e castração, mas também de novos conteúdos que sejam fonte da reserva narcísica do sujeito. Ou seja, diante da atualização de mensagens enigmáticas provocadas pelas vicissitudes do envelhecer, a presença do outro, tanto quanto no momento de constituição do sujeito, é o elemento fundamental para que ocorram traduções e, neste caso, destraduções seguidas de novas e menos mortíferas traduções.

\section{Transformações do eu: entre a melancolia e a perlaboração}

\section{Reações à passividade: formação reativa}

Ao ser levado para o lar feliz idade, a despeito do seu ateísmo, a família do silva colocou em sua cabeceira uma imagem de nossa senhora de fátima. Disseram-lhe que com o tempo ganharia um credo religioso, aprenderia a rezar e salvaria sua alma. Desde que colocaram a santa em seu quarto à sua revelia, antónio passou a relacionar-se com o objeto em muitos momentos com agressividade: "eu passara pelo meu quarto e partira as pombinhas à mariazinha". O silva dizia gostar dessa maldade, a qual ele associa a uma rebeldia aqui e acolá contrária a "ficar velhos e vulneráveis a todas as coisas": "caramba, temos de estar a postos para alguma retaliação, algum combate, não vá o mundo pensar que não precisa de tomar cuidado com as nossas dores" (mãe, 2016, p. 87).

O modo como silva relaciona-se com o objeto apresenta-se como uma tentativa de saída de uma posição passiva. Ao localizar o feito com a santa como uma retaliação, a narrativa nos dá elementos para considerarmos o ataque ao objeto uma hostilidade endereçada ao outro e a si mesmo quanto às mensagens traduzidas como incapacidades inerentes à velhice. Cabe ressaltar quão frequente é a desconsideração do credo e de outros posicionamentos do sujeito em virtude da sua condição de velho nas relações, mesmo em seu íntimo núcleo familiar. A dor psíquica muito facilmente é menos percebida ou tratada como algo desimportante por pessoas próximas ao idoso, estando os acometimentos físicos manifestados na concretude do corpo, como ponto de atenção quase exclusiva. Isso tem implicações subjetivas, relaciona-se tanto à atualização de mensagens enigmáticas, quanto às vias facilitadas para tradução do sexual atacante interno e externo. 
silva destruía também as flores colocadas no túmulo da laura por elisa, sua filha, todos os sábados após limpá-lo. O cemitério onde a esposa fora sepultada ficava ao lado do lar onde antónio passou a residir.

a elisa não estava a me censurar, o doutor bernardo é que me dizia aquelas coisas óbvias que se dizem às crianças e, por mais infantil que a situação fosse, eu não descia completamente à condição de menor, era outra coisa, um tempo completamente diferente e dotado de desafios completamente diferentes. (mãe, 2016, p. 202)

Poderíamos questionar que enigma é endereçado a antónio pela filha ao instalá-lo em uma instituição ao lado de um cemitério. Caberia também interrogar em que medida isso impele o silva ao trabalho psíquico vinculado às traduções do sexual. As suas reações ilustram tentativas de metabolização dos conteúdos sexuais a ele endereçados, junto ao trabalho de luto e de perlaboração na reconstrução do seu tecido narcísico.

Torna-se premente reafirmar que as pessoas próximas ao sujeito velho tendem a denominar as atitudes dele a partir do seu referencial como infantis, a infantilizá-lo em função do que interpretam como incapacidade em função dos acometimentos do corpo e dos atravessamentos que perpassam essa fragilização corporal. Porém, no sujeito idoso há um psiquismo já constituído e certa independência entre corpo e aparelho psíquico. Cabe ao sujeito dizer qual sentido tem seus gestos e ações. Para a psicanálise está em questão sempre, em todos os casos, o infantil e isso cabe diferenciar de uma infantilização.

\section{Sonhos traumáticos}

Desde que chegara ao lar, antónio passou a ter com frequência sonhos com o mesmo conteúdo. Durante os seus pesadelos encontrava-se em um dos quartos da instituição na ala da esquerda, a qual dava vistas ao cemitério. Lá, via dezenas de abutres voarem no céu e queria pedir para fecharem as janelas para que os pássaros não entrassem e o matassem, mas uma máscara de oxigênio tapava-lhe a boca e o impedia de gritar.

queria pedir que fechassem as portadas antes que os pássaros entrassem e me tomassem por morto. subitamente debicavam-me o corpo e eu ia permanecendo vivo e, até não ter corpo nenhum, a consciência não me abandonava. eu agoniava por achar que a morte não dependia do corpo, condenando-me a padecer daquela espera para todo o sempre. o estupor do corpo já desfeito e a 


\section{ARTIGOS}

morte sem o perceber, sem fazer o que lhe competia por uma crueldade perversa que eu nunca previra. (mãe, 2016, p. 52)

Após um dos seus sonhos angustiantes, silva vai para o quarto do pereira e em conversa com o amigo localiza os pesadelos como manifestação de medo, a despeito da sua vontade declarada de morrer: "acho que é uma forma de ter medo. julguei que não tivesse medo de nada. mas tenho. [...] de ser desfeito, de a morte me desfazer, não sei” (mãe, 2016, p. 231). Referindo-se ao sentimento de medo, antónio relata: "durante essas noites, eu acordava várias vezes à procura de entender onde estava e sentia o peito para me assegurar de que continuava inteiro" (mãe, 2016, p. 52).

Tanto nos sonhos quanto ao receber a notícia da morte da sua esposa e na situação em que joga o candeeiro ao chão e é acolhido pelo américo, aparece na fala de antónio conteúdos relacionados a devoramento, o que identificamos como uma metáfora que, ainda que precária, já é uma forma de elaboração da morte e da perda de si e do outro. Diz respeito a uma tradução possível do sexual como atacante interno, relacionado ao trauma. A representação-coisa, um conteúdo inconsciente desligado de qualquer sentido ou intencionalidade de comunicação, o qual veicula somente energia é, por isso mesmo, excitável e traumatizante, no sentido de uma cicatriz insistente que não cessa de se inscrever no psiquismo do sujeito (Laplanche, 1992b). Podemos tomar esse sonho em parte como realização de desejo no sentido mais masoquista e radical, pois ser devorado já é uma forma de controlar o pulsional. Todavia, há também a realização do desejo de permanecer vivo, por um momento, sem o corpo.

De um lado, o sujeito na velhice é impelido a traduzir seu novo corpo a partir dos códigos narrativos que lhe chegam vindo dos outros que o cercam ou de um contexto macro sociocultural, muitas vezes atrelados a uma valoração pejorativa do envelhecer. De outro, as suas traduções estão totalmente comprometidas com as representações-coisa, com desejos inconscientes há muito presentes em sua realidade psíquica, mas que agora passam por uma espécie de revisão, de atualização, tratando-se de uma edição da situação originária. Dessa forma, as vias facilitadas de tradução sobre a velhice são enlaçadas à história libidinal do sujeito. Os novos arranjos identificatórios do sujeito também são inundados pelo sexual, de modo que o eu compelido a uma (des)constituição continuará às voltas com as singulares manifestações do inconsciente pela via dos sintomas, dos sonhos etc. Assim, observamos o corpo tomado direta ou indiretamente como um enigma exigente de tradução vinculado tanto a transformações do eu quanto à atemporalidade e à alteridade do inconsciente. 


\section{O tabu da morte}

A perda de laura é relatada por antónio com grande tristeza e, diversas vezes, junto a uma vontade de também morrer: "morrer seria só a justiça de não me tornar uma imagem pálida do que fora. seria como corresponder a um padrão de vida emocional que não era justo que perdesse" (mãe, 2016, p. 51).

As visitas de silva ao cemitério onde a esposa encontrava-se sepultada, ao lado do lar feliz idade, tornaram-se uma rotina. Suas falas quanto à sua presença naquele lugar vão dando contorno aos pensamentos e sentimentos relacionados à morte. Observamos em sua narrativa a ambivalência de desejar morrer e, ao mesmo tempo, constatar a morte como tragédia.

afeiçoamo-nos à morte. é como se fôssemos cortejando a confiança dessa desconhecida, para nos encantarmos, quem sabe. ou para percebermos como the poderemos escapar ainda. coisas diversas e complementares, porque os nossos sentimentos vão oscilando entre uma necessidade de ultrapassar o impasse do fim da vida, e o trágico de que isso se reveste. a coragem tem falhas sérias aqui e acolá. e nós, que não somos de modo algum feitos de ferro, falhamos talvez demasiado, o que nem por isso nos torna covardes, apenas os mesmos de sempre. os mesmos vulneráveis e atordoados seres humanos de sempre. [...] sabemos todos rigorosamente uma ignorância semelhante. (mãe, 2016, p. 114)

Conforme Freud (1915/1996c) explica em "Reflexões para os tempos de guerra e morte", a morte de pessoas próximas com as quais tem-se vínculos afetivos, provoca no sujeito um rearranjo pulsional. Cada ente amado é "uma parte de seu próprio eu amado" (p. 303). As pessoas que amamos "constituem, por um lado, uma posse interna, componentes de nosso próprio ego; por outro, contudo, são parcialmente estranhos, até mesmo inimigos" (p. 308). Essa ambivalência pode ser atribuída também ao próprio eu do sujeito tomado como objeto de amor, o qual carece de investimento libidinal para não esfacelar-se. Na vivência de muitas e subsequentes perdas, diante do trabalho psíquico mobilizado pela força traumática que o colocou em processo, não causa espanto a instalação de um estado melancólico em decorrência do luto relacionado, inclusive, às transformações da própria instância egoica.

O grande desafio do senhor silva, assim como de muitos outros velhos, é a contingência de que os objetos nos quais investe afeto muitas vezes são pessoas também velhas e, portanto, mais passíveis de serem perdidas. No enredo do nosso personagem, aos cem anos morre o seu amigo esteves, o que impõe a antónio mais um luto e provoca um retorno a um estado de melancolia mais 


\section{ARTIGOS}

intenso. "a morte, afinal, dizia-lhe eu, vem mesmo de todos os lados e leva-nos tudo, mesmo aquilo a que nos agarramos para lhe fugir. [...] o esteves era como uma boia para que eu flutuasse, e agora vou ao fundo" (mãe, 2016, p. 158).

Após a morte de esteves, antónio passa a ficar mais deitado, de olhos fechados, fazendo as refeições no quarto e sem muito contato com os amigos. Entra em cena uma oscilação, de modo que ora ele encontra-se mais recolhido no quarto, ora o observamos recorrer aos recursos psíquicos que tem disponível. Por exemplo, ele volta a escrever secretamente cartas à dona marta, uma moradora do lar que aguardava semanalmente a chegada de alguma correspondência do seu marido mais jovem que a deixou naquele lugar e não deu mais notícias há anos. A fim de lhe dar alguma alegria, silva teve a ideia de passar-se por esse marido: "aquelas cartas eram sobre mim e ajudavam-me a pensar. ajudavam-me a transformar em literatura o que parecia nem ter verbalização possível" (mãe, 2016, p. 161).

Todavia, junto às perdas de objetos de amor externos, o próprio corpo vai gradualmente falhando de forma brutal. antónio começa a sentir falta de ar pouco tempo antes da morte de mais um amigo querido, desta vez o senhor pereira. Devido à falta de ar, precisou do uso de máscara de oxigênio e dos cuidados da enfermeira. O quadro clínico fora agravando, com tosses violentas e maior dificuldade para respirar. Passou a não conseguir levantar-se, comia com ajuda e passava os dias em certa penumbra porque, segundo ele, achavam que a pouca luz o faria descansar. Mas, o que lhe ocorria com frequência eram sonhos relacionados à angústia de morte. Em um estado clínico pior, silva encontra-se em um intenso processo de rever a vida:

eu precisava que me deixassem morrer inteiro. um monte de peles e carnes derrubadas, mas inteiro [...] porque eu precisava morrer consciente, recordando cada minuto do tempo com a minha laura, recordando como a vida se fizera em torno dela e da família, como me terá parecido que assim devia de ser um homem, como assim me havia bastado a cidadania. assente sobretudo no amor. não me tirem a consciência do amor e da sua perda. (mãe, 2016, p. 256)

O livro encerra-se com os amigos américo, cristiano e anísio no quarto de silva. antónio encontra-se em processo de elaboração do que fora até então a sua vida e manifesta angústia: "[...] sinto apenas angústia. a enfermeira entrou, aproximou-se de nós, perguntou, o que sente, senhor silva. e eu repeti, angústia, sinto angústia" (p. 257).

As lembranças são evocadas por silva como recurso para lidar com o sofrimento psíquico experimentado e, ao mesmo tempo, como exigência de trabalho de luto. Observamos ocorrer com antónio um momento intenso de 
ressignificação do passado. Porém, com o envelhecimento, o que evoca uma historiografia e tal ressignificação são modificações corporais e contingências muito peculiares a este momento da vida, frequentemente perpassadas pela morte tomada como enigma.

\section{Considerações finais}

A velhice abarca uma série de contingências vinculadas ao corpo, tornando-o enigma enquanto alteridade que ocasiona ataques ao eu, à sua consistência identificatória. Ao tomar o livro a máquina de fazer espanhóis (mãe, 2016) como material clínico, visualizamos na velhice perdas que levam ao trabalho psíquico, bem como uma imposição de trabalho psíquico que leva a perdas, estando ambas relacionadas a transformações do eu. Tal contexto impõe sobre o psiquismo uma potência traumática que é força motriz para uma atualização da situação originária acarretando em transformações do eu.

Seguindo o modelo de trabalho de Freud (1895/1986), consideramos importante partir do extremo, do psicopatológico, para abrir caminhos quanto ao funcionamento psíquico dito normal. Todavia, cabe ressaltar que não é nossa pretensão apontar uma atualização da situação originária e as transformações do eu do modo como explicitado neste trabalho como algo universal. A sua ocorrência, embora em tempos variados para cada sujeito, parece ser inevitável. Já o modo como ela ocorre não. É para uns angustiante, fator desintegrador e desorganizador do psiquismo, e, para outros, experimentada com menos dor psíquica. A possibilidade de certa generalização quanto ao funcionamento das engrenagens psíquicas relacionadas ao fenômeno da velhice, desde que vinculadas a um marco subjetivo manifestado pelo sujeito, fornece elementos teóricos que auxiliam a pensar no caso a caso, na clínica, tarefa que consideramos compromisso ético da psicanálise.

Agradecimentos: Agradecemos à Capes pelo fundamental apoio financeiro para a realização do trabalho de pesquisa no qual este artigo está embasado. Agradecemos também ao $\mathrm{CNPq}$ pela bolsa produtividade em pesquisa $\mathrm{CNPq}$ - Nivel 2, do segundo autor. 


\section{ARTIGOS}

\section{Referências}

Freud, S. (1986). Carta a Fliess de 25/5/1895. In J.M. Masson (Org.). Correspondência completa de Sigmund Freud para Wilhelm Fliess 1887-1904. Rio de Janeiro, RJ: Imago. (Trabalho original publicado em 1895).

Freud, S. (1996a). A sexualidade na etiologia das neuroses. In Edição Standard Brasileira das Obras Psicológicas Completas de Sigmund Freud (vol. III). Rio de Janeiro, RJ: Imago. (Trabalho original publicado em 1898).

Freud, S. (1996b). Delírios e sonhos na Gradiva de Jensen. In Edição Standard Brasileira das Obras Psicológicas Completas de Sigmund Freud (vol. IX). Rio de Janeiro, RJ: Imago. (Trabalho original publicado em 1907).

Freud, S. (1996c). Reflexões para os tempos de guerra e morte. In Edição Standard Brasileira das Obras Psicológicas Completas de Sigmund Freud (vol. XIV). Rio de Janeiro, RJ: Imago. (Trabalho original publicado em 1915).

Freud, S. (1996d). O estranho. In Edição Standard Brasileira das Obras Psicológicas Completas de Sigmund Freud (vol. XII). Rio de Janeiro, RJ: Imago. (Trabalho original publicado em 1919).

Freud, S. (2016). Sobre tipos neuróticos de adoecimento. In Neurose, psicose, perversão. Obras incompletas de Freud. Belo Horizonte, MG: Autêntica. (Trabalho original publicado em 1912).

Freud, S. (2017a). O método psicanalítico. In Fundamentos da clínica psicanalíticaObras incompletas de Freud. Belo Horizonte, MG: Autêntica. (Trabalho original publicado em 1904).

Freud, S. (2017b). Sobre psicoterapia. In Fundamentos da clínica psicanalítica Obras incompletas de Freud. Belo Horizonte, MG: Autêntica. (Trabalho original publicado em 1904).

Freud, S. (2017c). A análise finita e a infinita. In Fundamentos da clínica psicanalítica - Obras incompletas de Freud. Belo Horizonte, MG: Autêntica. (Trabalho original publicado em 1937).

Freud, S. (2019). Contribuições para a psicologia da vida amorosa. In Amor, sexualidade, feminilidade - Obras incompletas de Freud. Belo Horizonte, MG: Autêntica. (Trabalho original publicadoem 1912).

Goldfarb, D. C. (2014). Demências (2a ed.). São Paulo, SP: Casa do Psicólogo.

Laplanche, J. (1985). Vida e morte em psicanálise. Porto Alegre, RS: Artes Médicas.

Laplanche, J. (1992a). Novos fundamentos para a psicanálise. São Paulo, SP: Martins Fontes. (Trabalho original publicado em 1987).

Laplanche, J. (1992b). O inconsciente e o id. São Paulo, SP: Martins Fontes.

Laplanche, J. (1997). Freud e a sexualidade: o desvio biologizante. Rio de Janeiro, RJ: Jorge Zahar. 
mãe, v. h. (2016). a máquina de fazer espanhóis (2a ed.). São Paulo, SP: Globo Biblioteca Azul.

Ribeiro, P. C. (1997). Perlaboração: feminilidade e transformação do eu na técnica da psicanálise. Percurso, 1(18), 39-50. Recuperado de: <http://revistapercurso.uol. com.br/pdfs/p18_texto05.pdf $>$.

Ribeiro, P. C., \& Carvalho, M. T. M. (2001). “Tá tudo dominado!” Adolescência e violência originária. In M. R. Cardoso (Org.), Adolescência: reflexões psicanalíticas. Rio de Janeiro, RJ: NAU Editora.

\section{Resumos}

(Transformations of the ego in old age: psychic and clinical consequences)

This work aimed to develop subsidies for the psychoanalysis of the elderly based on Laplanche's theory. The recurrence of aging contingencies becoming a driving force for psychic work demands the analyst to think about the implications of old age for the individual and for clinical practice. We base our work on the hypothesis that vicissitudes of old age particularly touch the theme of original seduction. By reading the book a máquina de fazer espanhóis (mãe, 2016) ${ }^{4}$ as a clinic hearing, we articulate the reported peculiarities of old age to the theoretical aspects related to an update of the enigmatic messages and their consequences for the psyche. We consider that, due to old age, there are particular transformations of the ego that interfere in the processes of subjectivation and in the conduct of the clinical case.

Key words: Psychoanalysis, old age, ego, theory of generalized seduction

(Transformations du moi dans la vieillesse: consèquences psychiques et cliniques)

Ce travail vise à contribuer à la psychanalyse des personnes âgées à partir de la théorie de Jean Laplanche. La récurrence avec laquelle les contingences du vieillissement s'imposent comme moteur du travail psychique oblige l'analyste à réfléchir aux implications de la vieillesse pour le sujet et pour la pratique clinique. Nous partons de l'hypothèse que les vicissitudes de la vieillesse concernent particulièrement le thème de la séduction originale. De la lecture du livre a máquina de fazer

${ }^{4}$ We keep the spelling of the name of the author and also of his characters in lower case, as proposed by the writer. And also the quotes in Portuguese from Portugal, according to your writing. 


\section{ARTIGOS}

espanhóis (mãe, 2016), ${ }^{5}$ nous mettons en rapport les particularités de la vieillesse aux aspects théoriques pour mettre à jour les messages énigmatiques et leurs conséquences pour la psyché. Nous considérons que la vieillesse déclenche des transformations spéciales du moi qui interfèrent dans les processus de subjectivation et dans la conduite du cas clinique.

Mots clés: Psychanalyse, vieillesse, moi, théorie de la séduction généralisée

(Transformaciones del yo en la vejez: consecuencias psíquicas y para la práctica clínica)

El objetivo de este trabajo fue desarrollar, a partir de la teoría laplancheana, apoyos para el psicoanálisis de los ancianos. La recurrencia con la que las contingencias del envejecimiento se imponen como motor del trabajo psíquico requiere que el analista reflexione sobre las implicaciones de la vejez, tanto para el sujeto como para la práctica clínica. Partimos de la hipótesis de que las vicisitudes de la vejez se refieren, particularmente, al tema de la seducción originaria. A partir de la lectura del libro a máquina de fazer espanhóis (mãe, 2016), ${ }^{6}$ articulamos las peculiaridades de la vejez referidas a los aspectos teóricos relacionados a una actualización de los mensajes enigmáticos y a sus consecuencias para la psique. Consideramos que, debido a la vejez hay transformaciones particulares del yo que interfieren en los procesos de subjetivación y en la conducción del caso clínico.

Palabras clave: Psicoanálisis, vejez, yo, teoría de la seducción generalizada

Citação/Citation: Matos, V. B. \& Belo, F. R. R. (2021, set.). Transformações do eu na velhice: consequências psíquicas e para a prática clínica. Revista Latinoamericana de Psicopatologia Fundamental, 24(3), 641-664. http://dx.doi.org/10.1590/1415-4714.2021v24n3p641.9

Editora/Editor: Profa. Dra. Sonia Leite

Submetido/Submitted: 15.12.2019 / 12.15.2019 Aceito/Accepted: 26.12.2020 / 12.26.2020

${ }^{5}$ Nous conservons l'orthographe en minuscule du nom de l'auteur et aussi de ses personnages, selon la proposition de l'écrivain. Et aussi les citations en portugais du Portugal, selon votre écriture.

${ }^{6}$ Mantenemos la ortografía en minúsculas del nombre del autor y también de sus personajes, de acuerdo con la propuesta del escritor. Y también las citas en portugués de Portugal, según su escritura. 
Copyright: (C) 2009 Associação Universitária de Pesquisa em Psicopatologia Fundamental/ University Association for Research in Fundamental Psychopathology. Este é um artigo de livre acesso, que permite uso irrestrito, distribuição e reprodução em qualquer meio, desde que o autor e a fonte sejam citados / This is an open-access article, which permits unrestricted use, distribution, and reproduction in any medium, provided the original authors and sources are credited.

Financiamento/Funding: Este trabalho recebeu apoio da Coordenação de Aperfeiçoamento de Pessoal de Nivel Superior - Capes (Brasília, DF, Br) e do Conselho Nacional de Desenvolvimento Científico e Tecnológico - CNPq (Brasília, DF. Br) / This work is supported by Coordenação de Aperfeiçoamento de Pessoal de Nivel Superior - Capes (Brasília, DF, Br), and by Conselho Nacional de Desenvolvimento Científico e Tecnológico- CNPq (Brasília, DF. Br).

Conflito de interesses/Conflict of interest: Os autores declaram que não há conflito de interesses. / The authors declare that there is no conflict of interest.

\section{Vanessa Biscardi Matos}

Mestre em Estudos Psicanalíticos pela Universidade Federal de Minas Gerais - UFMG (Belo Horizonte, MG, Br).

Rua dos Goitacazes, 14, sala 304

30190-908 Belo Horizonte, MG, Br

vanessabiscardi.psi@gmail.com

https://orcid.org/0000-0002-4443-245X

\section{FÁbio Roberto Rodrigues Belo}

Doutor em Estudos Literários pela Universidade Federal de Minas Gerais - UFMG (Belo Horizonte, MG, Br); Docente do Departamento de Psicologia na mesma Universidade.

Universidade Federal de Minas Gerais - FAFICH

Avenida Antônio Carlos, 6627, gabinete 4034

31270-901 Belo Horizonte, MG, Br

fabiobelo76@gmail.com

https://orcid.org/0000-0002-5803-1745

This is an open-access article, which permits unrestricted use, distribution, and reproduction in any medium for non-commercial purposes provided the original authors and sources are credited. 